\title{
Diagnóstico e adequações do sistema de resfriamento da água de beber para fêmeas suínas em lactação e gestação visando melhorias nos índices produtivos
}

\author{
Diagnosis and adaptations of the drinking water cooling system for lactating and gestating swine \\ females with a view to improving production rates \\ Diagnóstico y adaptaciones del sistema de enfriamiento de agua potable para hembras porcinas \\ lactantes y gestantes con miras a mejorar los índices de producción
}

Recebido: 24/03/2021 | Revisado: 29/03/2021 | Aceito: 09/04/2021 | Publicado: 13/04/2021

\author{
Lucas Barbosa Marques \\ ORCID: https://orcid.org/0000-0002-8774-2968 \\ Universidade Federal de Minas Gerais, Brasil \\ E-mail: eng.lucasbm@outlook.com \\ Isabella Barbosa Marques \\ ORCID: https://orcid.org/0000-0001-6879-5880 \\ Universidade Estadual Paulista, Brasil \\ E-mail: isabella.marques@unesp.br \\ Leonardo França da Silva \\ ORCID: https://orcid.org/0000-0002-9710-8100 \\ Universidade de Federal Viçosa, Brasil \\ E-mail: leonardo.silva@ufv.br \\ Lindeneia de Jesus Matias \\ ORCID: https://orcid.org/0000-0003-4773-8806 \\ Universidade Federal de Minas Gerais, Brasil \\ E-mail: lindineiam@gmail.com \\ Bruno Alexander Nunes Silva \\ ORCID: https://orcid.org/0000-0003-3791-8088 \\ Universidade Federal de Minas Gerais, Brasil \\ E-mail: brunosilva@ufmg.br \\ Irene Menegali \\ ORCID: https://orcid.org/0000-0001-5323-4693 \\ Universidade Federal de Minas Gerais, Brasil \\ E-mail: imenegali@ufmg.br
}

\begin{abstract}
Resumo
Manejar as porcas em lactação adequadamente quando submetidas ao estresse térmico é fundamental para a indústria suinícola. A alta temperatura combinada com a umidade elevada faz com que o desempenho seja comprometido das matrizes em lactação, como efeitos desse estresse provocado pelo calor, as porcas diminuem a ingestão de alimento e consequentemente diminui a produção de leite na leitegada. Desta forma, objetivou-se com este trabalho adequar o sistema de resfriamento de água de beber existente em funcionamento na granja suinícola na Fazenda Experimental Professor Hamilton de Abreu Navarro, para que promova a recirculação da água utilizada para dessedentar as fêmeas suínas, visando manter a temperatura em níveis adequados para o consumo para os animais. O projeto foi constituído buscando melhorar de maneira econômica e eficiente. Instalou equipamentos, adicionou novas tubulações e uma motobomba com controlador de tempo para fazer a recirculação de água. Após implantação, a água da tubulação se manteve mais homogênea e em temperaturas inferiores a da água da rede e ao ambiente. Concluiu-se que houve melhoria no sistema, o que possibilitará estudos futuros sobre a influência da água resfriada nos índices zootécnicos.

Palavras-chave: Suinocultura; Bem estar animal; Água resfriada.
\end{abstract}

\begin{abstract}
Managing lactating sows properly when subjected to thermal stress is essential for the pig industry. The high temperature combined with the high humidity, causes the performance of the lactating matrices to be compromised, as the effects of this heat stress, the sows decrease the food intake and consequently decrease the milk production in the litter. In this way, the objective of this work was to adapt the existing drinking water cooling system in operation at the pig farm at Professor Hamilton de Abreu Navarro Experimental Farm, so that it promotes the recirculation of the water used to feed the swine females, in order to maintain the temperature at levels suitable for consumption by animals. The project was created in order to improve in an economical and efficient way. It installed equipment, added new pipes and a time-controlled motor pump to recirculate the water. After implantation, the water in the pipeline remained more homogeneous and at temperatures lower than that of the mains water and the environment. It
\end{abstract}


was concluded that there was an improvement in the system, which will allow future studies on the influence of chilled water on zootechnical indexes.

Keywords: Pig farming; Animal welfare; Chilled water.

\section{Resumen}

El manejo adecuado de las cerdas lactantes cuando se someten a estrés térmico es esencial para la industria porcina. La alta temperatura combinada con la alta humedad, hace que el desempeño de las matrices lactantes se vea comprometido, ya que los efectos de este estrés térmico, las cerdas disminuyen la ingesta de alimento y consecuentemente disminuyen la producción de leche en la camada. Así, el objetivo de este trabajo fue adecuar el sistema de enfriamiento de agua potable existente en funcionamiento en la granja porcina de la Granja Experimental Profesor Hamilton de Abreu Navarro, de manera que promueva la recirculación del agua utilizada para la alimentación de las hembras porcinas, con el fin de mantener la temperatura a niveles adecuados para el consumo de los animales. El proyecto fue creado con el fin de mejorar de manera económica y eficiente. Se instaló equipo, se agregaron nuevas tuberías y una motobomba con un controlador de tiempo para hacer la recirculación del agua. Después de la implantación, el agua de la tubería se mantuvo más homogénea y a temperaturas inferiores a las del agua de red y del medio ambiente. Se concluyó que hubo una mejora en el sistema, lo que permitirá futuros estudios sobre la influencia del agua enfriada en los índices zootécnicos.

Palabras clave: Cría de cerdos; Bienestar de los animales; Agua helada.

\section{Introdução}

O Brasil é o quarto maior produtor de suínos do mundo. Dentre os estados brasileiros criadores de suínos, Santa Catarina se destaca com o maior rebanho e a maior produção. Essa atividade garante renda e desenvolvimento social no país, já que emprega imensa mão-de-obra, seja ela nas granjas produtoras, seja ela na agroindústria (ABPA, 2020; Machado, 2015). A criação intensa de suínos se tornou viável devido aos avanços tecnológicos, tanto em genética quanto em nutrição, controle ambiental e manejos racionais, o que possibilitou melhora e ganho de todo o sistema de produção (Cordeiro et al., 2007; Machado, 2015; Dias, 2014 Sampaio et al., 2007; Miele, Machado, 2010). A produção nacional vem aumentando bastante, buscando suprir a necessidade de produção de proteína animal, garantindo alimentação de qualidade e com maior segurança. (Mota et. al., 2019).

A partir da década de 70, a suinocultura do Brasil, tornando-se um sistema intensivo de confinamento, priorizando maiores ganhos econômico, eficiência alimentar, melhores condições sanitárias e de manejo dos animais e com isso ocorreu um aumento na produção de suínos no país. Com a expansão do sistema de confinamento, consequentemente surgiu à necessidade de se conhecer melhor a relação entre os animais com o ambiente em que encontrar-se inseridos (Sampaio et al., 2007).

Neste contexto produtivo é fundamental enfatizar a importância do uso de modificações secundárias para o sistema intensivo, quando as condições climáticas naturais não são suficientemente eficazes para controlar a temperatura no interior das instalações e assim causando um maior desconforto térmico para os animais. Dessa forma, a necessidade de se implantar sistemas que tem diversas finalidades, como resfriar o piso, a água, o ar e outros que promovam a circulação de ventos nas unidades suinícolas (Sartor et. al., 2004; Ferreira, 2016; Renaudeua et. al., 2001; Mota et. al., 2019; Vermeer et. al., 2009; Mamede, 1980).

O Brasil é um país de clima tropical, caracterizado por conter temperaturas elevadas na maior parte do ano, no qual causa grande desconforto térmico provocado pelas altas temperaturas e consequentemente provocar perdas significativas na produção. (Renaudeua et. al., 2001; Ferreira, 2016; Baêta; Souza, 2010; Campos et. al., 2008). Desta forma, manejar as porcas em lactação adequadamente quando submetidas ao estresse térmico é fundamental para a indústria suinícola. A alta temperatura combinada com a umidade elevada faz com que se tenha um franco desempenho das matrizes em lactação. (Morales, 2010; Renaudeau et al., 2003; Sarubbi et.al., 2010; Costa; Martins, 2013). 
Tendo em vista os argumentos mencionados, objetivou-se com esta pesquisa adequar o sistema existente em funcionamento na granja suinícola na Fazenda Experimental Professor Hamilton de Abreu Navarro - FEHAN - UFMG, para que promova a recirculação da água utilizada para dessedentar as fêmeas suínas, visando manter a temperatura em níveis adequados para o consumo. Tendo a necessidade de definir o intervalo de tempo adequado para a promover a recirculação da água no novo sistema.

\section{Metodologia}

\section{Caracterização da área de estudo}

O experimento foi conduzido na Fazenda Experimental Professor Hamilton de Abreu Navarro (FEHAN), do Instituto de Ciências Agrárias da Universidade Federal de Minas Gerais, Campus Montes Claros. O clima da cidade é considerado Aw (tropical) segundo a classificação de Köppen, com chuvas no verão e outono.

\section{Descrição do trabalho}

O trabalho foi realizado em três etapas sendo divididas:

Fase 1- Diagnóstico dos principais problemas existentes no sistema de água para consumo na unidade de produção suinícola da FEHAN.

Fase 2 - Proposta de alterações em relação a estrutura física, com o intuito de melhorar a qualidade da água fornecida aos animais confinados.

Fase 3 - Foi realizado também o teste para averiguar a eficiência do sistema de resfriamento.

\section{Coleta de Dados}

As características relacionadas aos aspectos construtivos como as dimensões, quais materiais foram empregados para construção, posição geográfica e altura da granja, foram obtidos tanto por entrevista com os trabalhadores da granja, como por medição direta e análise visual e fotografias (Mota et. al., 2019). As verificações dos níveis de temperatura dentro da granja foram obtidas por meio de um Termômetro digital infravermelho com mira laser da marca Benetech, modelo GM - 300. Mediu-se também a temperatura em três pontos diferentes, uma na gestação, três na maternidade, com o intuito de saber se o sistema implantado teve eficiência. As tubulações existentes foram medidas a fim de verificar o tamanho.

Após a coleta de dados, foi realizada a análise dos mesmos, baseando em comparações com outros dados de pesquisas já realizadas no mesmo local, levando em consideração as características analisadas. A partir disso, fez-se um diagnóstico sobre a real situação da instalação suinícola, especificamente o sistema de água fria, propondo medidas para melhorar, buscando um projeto ideal que atenda às necessidades dos animais e traga maior bem estar.

\section{Resultados e Discussões}

\section{Caracterização da FEHAN}

As estruturas da granja suinícola da Fazenda Experimental Professor Hamilton Abreu Navarro estava em pleno funcionamento, com presença de animais. A granja era classificada como de pequeno porte de ciclo completo (MOTA et. al., 2019). 


\section{Análise estrutural do setor de maternidade e gestação}

As matrizes iam para maternidade cinco dias antes do parto, ficando cada fêmea em uma baia individual, sendo esta dividida em três partes: área da matriz, área de amamentação dos leitões e circulação e o escamoteador. O último tinha um sistema de aquecimento para os leitões, em que eram usadas lâmpadas incandescentes comuns para produção de calor. Nessa parte do sistema, tinha a presença de oito gaiolas, divididas, ficando quatro em cada lado. O piso das gaiolas era ripado para facilitar o escoamento dos dejetos e água.

Após a confirmação da prenhes, as fêmeas eram levadas para as gaiolas de gestação. O sistema de gestação possuía as mesmas características da maternidade, ambiente parecido, mesma altura do pé direito, mesmo telhado e recebem a mesma água fria provida da caixa que tem sua água resfriada. Cada vaga é individual e as fêmeas permanecem nesse setor até iminência do nascimento dos leitões, três dias a uma semana antes do parto.

\section{Diagnóstico do sistema de resfriamento de gestação da FEHAN e alterações propostas}

O sistema existente era todo fechado a água que saía do mesmo ia até as chupetas e bebedouros através da força da gravidade. Com isso não havia recirculação de água na maternidade, pois a mesma situava-se longe da caixa d'água, fazendo com que o calor provido do ambiente aquecesse a água que se encontrava na tubulação. Desta maneira a água que sai da caixa d'água, percorria o sistema, e não sendo ingerida pelas matrizes, ficando parada no sistema, ficando aquecida com passar do tempo, pelo calor do ambiente, conforme o apresentado na (Figura 1A). Sendo assim, foi visto a necessidade de se criar um novo sistema, de forma que a água não mais ficasse parada, ocorrendo a recirculação.

Optou-se por um sistema de recirculação que era delimitado por um período de tempo, desta forma foi inserida uma motobomba no sistema que funcionava de maneira que nas horas de maior temperatura ao longo do dia, período correspondente entre 12 e 18 horas, a motobomba era acionada em um menor espaço de tempo trinta em trinta minutos.

Já nos horários que as temperaturas encontravam mais amenas (início da manhã e à noite), o sistema era acionado de uma em uma hora. Analisando o que poderia ser feito e qual seria a melhor forma de fazer essa água circular no sistema da forma mais eficiente e com menor custo, foram criadas novas ramificações no sistema de tubulação, isolando parte do sistema, abrindo novos caminhos para que a água possa circular e voltar para a caixa d'água, buscando manter a temperatura entre $16 \mathrm{e}$ $20^{\circ} \mathrm{C}$ no sistema, conforme o apresentado no layout (Figura 1B). 
Figura 1. Sistema de água refrigerada e água em temperatura ambiente na unidade suinícola (A). Sistema de água refrigerada e água em temperatura ambiente após a intervenção (B).

(1.A)

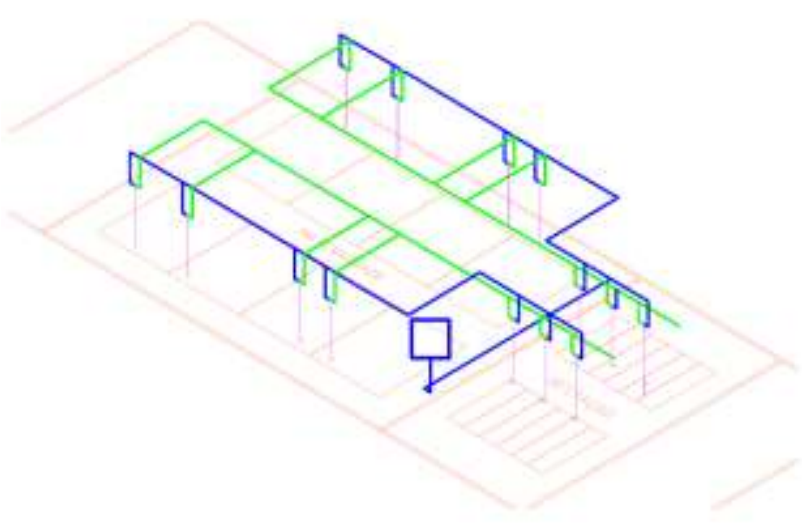

1.B)

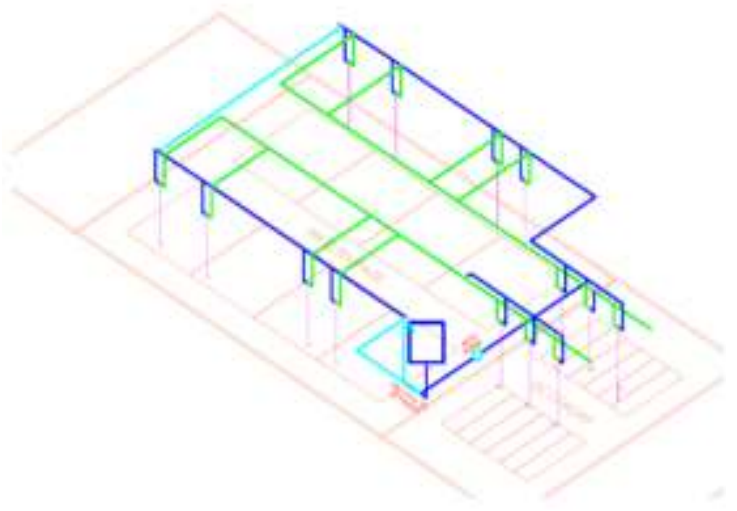

Legenda da FIG. 1 A: linha verde - tubulação contendo água em temperatura ambiente. Linha azul royal - tubulação contendo água resfriada a partir da caixa d'água. FIG.1 B Legenda: Linha verde - tubulação contendo água em temperatura ambiente, Linha azul Royal - tubulação contendo água resfriada a partir da caixa d'água Linha azul capri - tubulação contendo água fria que foi adicionada ao sistema.

Fonte: Autores (2019).

No novo sistema proposto faz com que a entrada de água por gravidade passou a ser por dois pontos, antes se utilizava um único ponto e faziam-se as derivações para ambos os lados da unidade suinícola. Agora com o incremento da válvula de retenção, usada para fazer a circulação da água, quando o motobomba está em funcionamento, percorre água resfriada com a ajuda da gravidade, aumentando com isso a vazão do sistema.

\section{Alterações executadas no sistema de resfriamento de água}

A primeira alteração no sistema foi através da tubulação que liga o final dos dois sistemas para proporcionar circulação da água através da motobomba, garantindo assim que a água que sai resfriada da caixa d'água percorra toda a extensão da tubulação, permitindo que todo o sistema apresente a mesma temperatura.

A tubulação que a instalação possuía tinha um diâmetro de 3/4", neste sentido, todas as adaptações seguiram o diâmetro já adotado. Outra parte modificada foi o fechamento da primeira derivação, sendo feita uma nova tubulação ligando ao início, perto da saída de água da caixa. $\mathrm{O}$ intuito dessa parte do sistema foi promover um caminho mais fácil para a água que sai por gravidade. A partir da válvula de retenção foi criada uma nova tubulação para levar a água que fica no sistema para a caixa Figura -2A. Na Figura - 2.B mostra a ligação que foi feita através de um tubo de PVC revestido com material isolante de cor preta, afim de ligar os dois traçados antigos que ao final do sistema antigo ficava fechado. Após a instalação, os dois traçados tornaram um só, unificando o sistema. 
Figura 2. A Válvula de retenção instalada após a derivação. B Ligação por uma nova tubulação dos dois traçados antigos.
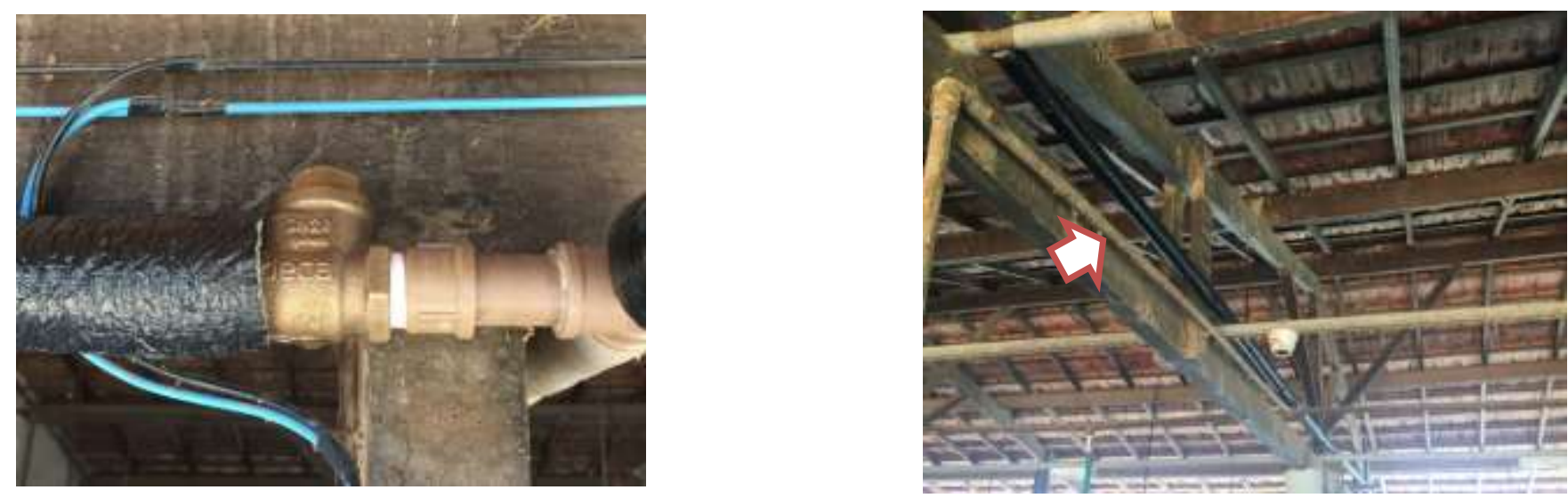

Fonte: Retirado do arquivo pessoal dos autores (2019).

Outra alteração foi a adição de uma válvula no início da tubulação, após a saída de água da caixa. Foi escolhido o modelo Válvula de Retenção Horizontal Portinhola 3/4 polegadas, da marca Deca devido a atender as necessidades do projeto e o diâmetro da tubulação já existente. (FIG. 1A) Foi feita então uma nova tubulação a partir da implantação da mesma. Sua função era basicamente permitir que a água resfriada passasse pela mesma enquanto o sistema não estiver sendo pressurizado com atuação somente da força da gravidade e impedir que a água presente na tubulação seja succionada pelo conjunto moto bomba. Com isso, o sistema permaneceu todo aberto enquanto não se tinha pressurização e após o mesmo ficar sobre pressão, a válvula cria um caminho que leva a água que sai da tubulação para a caixa d'água. A válvula de retenção tinha a função de não deixar a água que estava na tubulação ser puxada pela bomba centrífuga. Após a bomba ser desligada, a válvula abria e deixava passar água que sai da caixa, utilizando para isso a altura manométrica disponível no sistema.

As alterações propostas no conjunto motobomba foram visando promover a circulação da água, já que antes da implantação a mesma ficava parada na tubulação e ao final do sistema, a água já não estava mais na temperatura que se desejava. A escolha do modelo Bomba Periférica 1/2" Hp - BP500 - Intech Machine, com altura manométrica de $26 \mathrm{~m}$ se deu devido a ela atender a necessidade do projeto, om altura manométrica de $26 \mathrm{~m}$

Com isso, à medida que a temperatura do ambiente aumentasse a água também aumentava sua temperatura. Após o incremento do conjunto, pode-se fazer a água movimentar e garantir que na parte mais distante da tubulação, a temperatura fosse a mesma da saída da caixa. Outra função foi a de substituir a água parada que aqueceu na tubulação pela água resfriada que se encontra na caixa d'água. Para pressurizar o sistema fez-se o uso de uma bomba centrífuga para poder fazer a água circular por todo o sistema.

\section{Controle do tempo de funcionamento do sistema}

Para controlar o tempo em que o motobomba fica ligada e em que momento ela deve funcionar, inseriu-se um Programador De Tempo Digital Biv da marca Foxlux, com vinte diferentes programações. Com isso, ao longo de um período de vinte e quatro horas, o sistema funcionará vinte vezes.

$\mathrm{O}$ tempo de funcionamento foi definido em cinco minutos, o suficiente para que a água percorra toda a tubulação e se mantenha em temperatura constante. Considerando o dia de funcionamento, a primeira hora que a bomba centrífuga funciona são as sete horas da manhã. Nesse tempo, ela funciona basicamente de uma em uma hora até às dez horas da manhã. Após esse período, o sistema passa a circular forçado de meia em meia hora. Garantindo que a água esteja na temperatura ideal.

Olsson e Andersson (1985) mostra que existe um pico de ingestão de água, sendo que pela manhã ele é duas horas após a ingestão de alimento e de uma hora e meia pela tarde no período da tarde. Com isso, manter valores de temperatura 
ideal potencializa o consumo de água e influencia diretamente o consumo. Como na maternidade a ração é automática, a sempre o estímulo para matriz levantar para comer e consequentemente ingerir.

\section{Aplicação de isolante térmico}

Para garantir que a temperatura ambiente influencie na temperatura da água no sistema, fez-se o isolamento de toda tubulação presente, desde a que sai da caixa d'água até os bebedouros das matrizes em lactação. Utilizou para isso o Tubo Isolante Polipex 3/4 polegadas de 2 Metros, elastomérico preto. Com isso, garantiu um maior tempo de conservação da temperatura da água. Como não foi possível fazer a circulação da água abaixo do hidrômetro, devido a esse ter a função de medir a quantidade de água ingerida pelos animais, o isolamento se fez necessário, já que nessa parte do sistema, a água fica parada, movimentando apenas quando os animais consomem água.

Após o isolamento, a água se manteve com a temperatura almejada por um período maior, estando com a temperatura adequada, sendo que ao se misturar com a água presente na tubulação acima do hidrômetro, a temperatura ficasse ideal. Essa parte do sistema era a que mais exibia problema com a água em toda a granja, sendo ela a parte principal a se melhorar.

\section{Teste para averiguar a eficiência do sistema de resfriamento}

Após implantação do projeto proposto, optou-se em realizar medidas de temperatura ao longo de sete dias, dispostas em quatro horários diferentes: às 08 horas, às 11 horas, às 15 horas e às 18 horas. Foram medidas temperaturas em seis pontos distintos, sendo três pontos em três bebedouros diferentes na maternidade, um ponto na chupeta da gestação, um na água da rede de abastecimento e outro no centro da unidade suinícola.

A escolha de mais pontos na maternidade se deu devido ao fato de que nas baias o aquecimento da água era mais evidente que na gestação, pois as mesmas ficavam mais distante do freezer usado para refrigerar a água. Optou-se por horários em que a temperatura ambiente estava mais amena, as oito da manhã, horários em que a temperatura ambiente começa a se elevar, as onze da manhã, as 15 horas, horário de maior radiação solar entre todos escolhidos e as 18 horas, quando a temperatura começa a cair.

A Tabela - 1, mostra os dados coletados, os horários em que se fez as medições de temperaturas, as temperaturas médias nos bebedouros, as temperaturas médias do ambiente em cada horário que foi colhido os dados, as temperaturas médias da água na caixa d'água e as temperaturas médias da água da rede de abastecimento, todas em ${ }^{\circ} \mathrm{C}$.

Tabela 1 - Temperaturas médias medidas ao longo de sete dias em sete pontos diferentes na unidade suinícola.

\begin{tabular}{cccccccc}
\hline \multirow{2}{*}{$\begin{array}{c}\text { Horário } \\
\text { (Horas) }\end{array}$} & \multicolumn{3}{c}{$\begin{array}{c}\text { Temperatura da água no bebedouro da maternidade } \\
\text { e Gestação }\left({ }^{\circ} \mathrm{C}\right)\end{array}$} & $\begin{array}{c}\text { Temperatura } \\
\text { Ambiente }\left({ }^{\circ} \mathrm{C}\right)\end{array}$ & $\begin{array}{c}\text { Temperatura da } \\
\text { água na caixa }\left({ }^{\circ}\right. \\
\text { C })\end{array}$ & $\begin{array}{c}\text { Temperatura da } \\
\text { água na rede }\left({ }^{\circ} \mathrm{C}\right)\end{array}$ \\
\cline { 2 - 5 } & Gaiola 1 & Gaiola 2 & Gaiola 3 & Gestação & & 21,0 & 27,0 \\
\hline $08: 00$ & 21,1 & 20,6 & 20,4 & 19,7 & 26,7 & 22,3 & 29,5 \\
$11: 00$ & 23,0 & 22,8 & 23,2 & 22,1 & 30,1 & 24,6 & 30,5 \\
$15: 00$ & 23,3 & 23,2 & 22,8 & 22,4 & 30,9 & 25,4 & 30,5 \\
$18: 00$ & 24,1 & 24,1 & 24,3 & 23,5 & 30,1 & 23 \\
\hline
\end{tabular}

Fonte: Autores (2019).

A partir dos dados obtidos podemos notar que após a implantação do projeto de melhoria do sistema de resfriamento conseguiu-se temperaturas mais homogêneas. Nota-se que a temperatura da água na gestação é na maioria das vezes menor que nas gaiolas. Isso se deve ao fato de que ela fica mais próxima da caixa de armazenamento de água. Nota-se que mesmo nos 
dias mais quentes, conforme dados da Tabela - 2, a temperatura da água na tubulação que abastece as gaiolas da maternidade e da gestação era em média $7^{\circ} \mathrm{C}$ mais fria que a temperatura do ambiente. Segundo, Bonett e Monticelli (1998) e Ferreira (2016), preconizam que na fase de gestação e lactação, as fêmeas suínas necessitam de maiores quantidades de água, daí a necessidade de se preocupar em manter uma boa temperatura e aumentar o consumo de água nessas fases.

O Gráfico - 1 mostra a média dos dados colhidos ao longo dos sete dias. Nota-se a diferença da temperatura que chegaria às baias e na gestação se não tivesse o sistema de resfriamento implantado. Para Oliveira (2010), Oliveira (2009), enfatizam que os suínos devem ingerir uma quantidade de água diária que corresponde a 5 ou $6 \%$ do seu peso corporal. Segundo Palhares (2011), se os suínos não ingerir a quantidade de água suficiente para realizar suas funções metabólicas isso influenciará diretamente no consumo de ração, fazendo com a ingestão seja menor, refletindo nos índices zootécnicos. Daí a necessidade de fornecer água de qualidade e em temperatura adequada.

Gráfico 1 - Temperatura média da água resfriada nas baias, gestação, temperatura da água rede de fornecimento e temperatura ambiente.

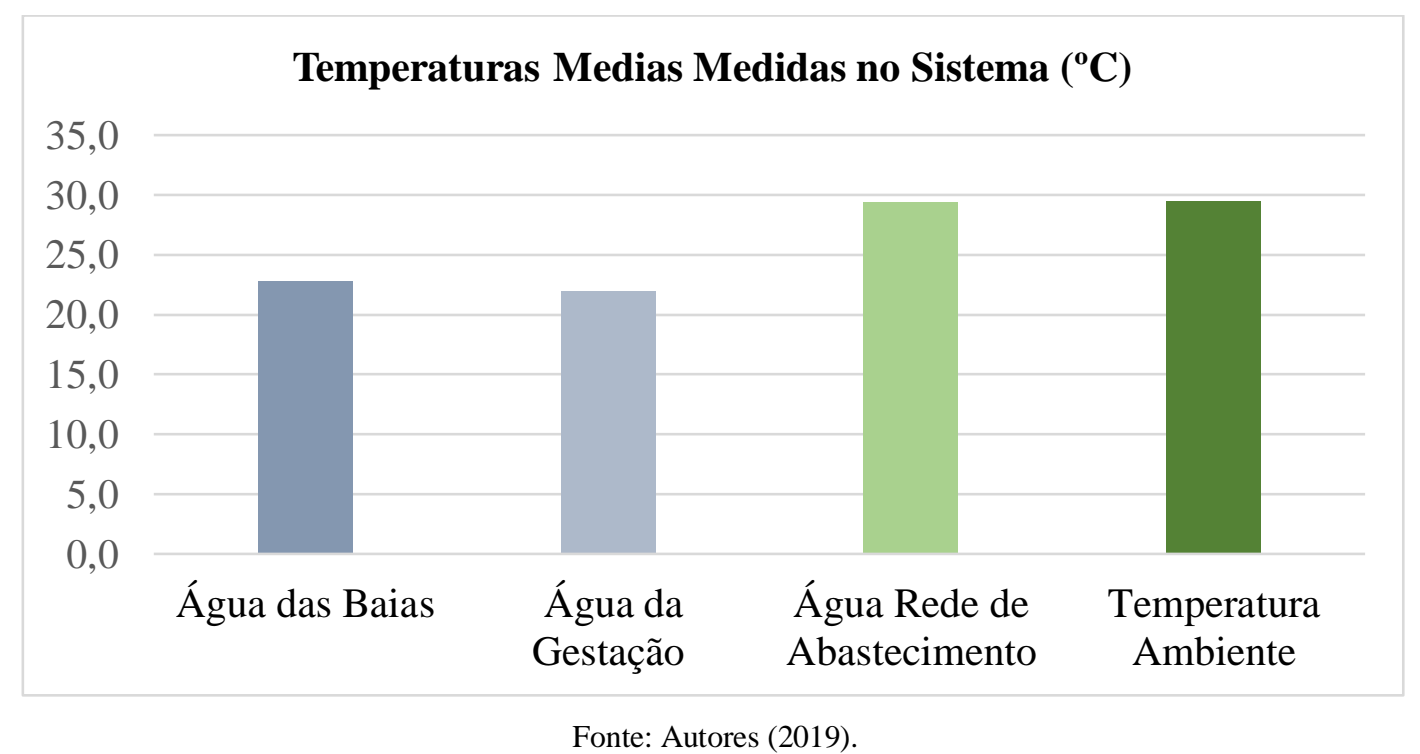

Cabe ressaltar, que o controle de temperatura da água é de suma importância, tanto para o consumo direto da própria água como para o consumo indireto de ração. Ferreira (2016) e Baeta e Souza (2010) evidenciam que a temperatura da água e do ambiente, influência no consumo de água pelos suínos. Quando se tem temperaturas altas do ambiente e temperatura da água em torno de $21^{\circ} \mathrm{C}$, nota-se maior consumo de água pelos animais. Dessa forma, fica evidente a importância desse trabalho para melhorar o consumo de água pelas matrizes suínas, já que em regiões tropicais a temperatura ambiente ao longo do ano se encontra elevada, sendo importante resfriar a água para aumentar a ingestão pelos animais.

\section{Conclusões}

As alterações propostas no projeto tinham como objetivo manter a temperatura no sistema de resfriamento da água, o qual proporcionou níveis de temperatura da água mais uniforme ao longo do dia. A água no sistema de resfriamento é em média $7^{\circ} \mathrm{C}$ mais fria que a temperatura ambiente. Manteve-se também a temperatura mais homogênea em toda extensão da tubulação. 


\section{Referência}

ABPA-Associação Brasileira De Proteína Animal (2019). Relatório anual.

Baêta, F. C. \& Souza, C. F. (2010). Ambiência em Edificações Rurais: Conforto térmico. (2a ed.), Editora UFV.

Bonett, L. P., \& Monticelli, C. J. (1998). Suínos: o produtor pergunta, a Embrapa responde. Brasília, DF: Embrapa-SPI; Concórdia: Embrapa-CNPSA, 1998.

Campos, J. A., Tinôcim I. F.F. \& Baêta, F. C. (2008). Ambiente térmico e desempenho de suínos em dois modelos de maternidade e creche. Revista Ceres, (55), 187-93.

Cordeiro, M. B., Tinôco, I. D. F. F., Oliveira, P. A. V. D., Menegali, I., Guimarães, M. C. D. C., Baêta, F. D. C., \& Silva, J. N. D. (2007). Efeito de sistemas de criação no conforto térmico ambiente e no desempenho produtivo de suínos na primavera. Revista Brasileira de Zootecnia, 36(5), $1597-1602$.

Costa, A. N., \& Martins, T. D. D. (2013). Issues and challenges in meeting well-being concerns of sows and litters. CAB Reviews, 8(048), 1-8.

Dias, C. P. (2014). Bem-estar na suinocultura. (Thesis, tesis, tese (Doutorado em Ciência Animal) - Universidade Estadual de Londrina, Londrina).

Ferreira, R. A. (2016). Maior produção com melhor ambiente: para aves, suínos e bovinos. (3a ed.), Editora Viçosa.

Lima, A. L., Oliveira, R. F. M. D., Donzele, J. L., Fernandes, H. C., Campos, P. H., \& Antunes, M. V. D. L. (2011). Resfriamento do piso da maternidade para porcas em lactação no verão. Revista Brasileira de Zootecnia, 40(4), 804-811.

Machado, J. (2015). Cenário Carnes, (2014-2015). In: Associação Brasileira de Proteína Animal-ABPA. Relatório Anual de Atividades.

Mamede, R. (1980). Consumo de água e relação água/ração para suínos em crescimento e terminação. 1980.32 p (Doctoral dissertation, Dissertação (Mestrado em Zootecnia). Universidade Federal de Minas Gerais, Belo Horizonte).

Miele, M. M. (2010). Panorama da carne suína brasileira.

Morales, O. Aspectos produtivos de fêmeas suínas e suas leitegadas em diferentes sistemas de ambiência na maternidade. 2010 (Doctoral dissertation, Tese (Mestrado em Medicina Veterinária). Universidade Federal do Rio Grande do Sul).

Mota, L. T., da Silva, L. F., Menegali, I., \& Silva, B. A. N. (2019). Análise Estrutural De Instalações Suinícolas Visando Melhorias Nos Índices De Conforto Térmico. Energia Na Agricultura, 34(3), 389-398.

Nagai, M., Hachimura, K., \& Takahashi, K. (1994). Water consumption in suckling pigs. Journal of Veterinary Medical Science, $56(1)$, $181-183$.

Oliveira, M. V. (2010). Recursos hídricos e a produção animal-legislação e aspectos gerais. Simpósio Produção Animal e Recursos Hídricos, 1.

Oliveira, P. A. V. (2009). Uso racional da água na suinocultura. EMBRAPA - Suínos e Aves.

Olsson, O., \& Andersson, T. (1985). Biometric considerations when designing a valve drinking system for growing-finishing pigs. Acta Agriculturae Scandinavica, 35(1), 55-66.

Palhares, J. C. P., \& Miranda, C. R. (2007). Gestão Ambiental da propriedade suinícola. Gestão Ambiental na Suinocultura. Brasília, DF: Embrapa Informação Tecnológica, 287-302.

Penz, J., \& Viola, E. S. (1995). Potabilidade e exigências de água nas diferentes faixas etárias. In Congresso Brasileiro De Veterinários Especialistas Em Suínos. 7, 57-67.

Perdomo, C. C. (1995). Avaliação de sistemas de ventilação sobre o condicionamento ambiental e o desempenho de suínos na fase de maternidade. UFRGS, 239.

Renaudeau, D., \& Noblet, J. (2001). Effects of exposure to high ambient temperature and dietary protein level on sow milk production and performance of piglets. Journal of animal science, $79(6), 1540-1548$.

Renaudeau, D., Noblet, J., \& Dourmad, J. Y. (2003). Effect of ambient temperature on mammary gland metabolism in lactating sows. Journal of Animal Science, 81(1), 217-231.

Rodrigues, N. E. B., Zangeronimo, M. G., \& Fialho, E. T. (2010). Adaptações fisiológicas de suínos sob estresse térmico. Revista Eletrônica Nutritime, 7(2), 1197-1211.

Sampaio, C. A. D. P., Nääs, I. D. A., Salgado, D. D., \& Queirós, M. P. (2007). Avaliação do nível de ruído em instalações para suínos. Revista Brasileira de Engenharia Agrícola e Ambiental, 11(4), 436-440.

Sartor, V., Souza, C. D. F., \& Tinoco, I. D. F. (2004). Informações básicas para projetos de construções rurais: instalações para suínos. Universidade Federal de Viçosa.

Sarubbi, J., Rossi, L. A., Moura, D. J. D., Oliveira, R. A. D., \& David, E. (2010). Utilização de energia elétrica em diferen tes sistemas de aquecimento para leitões desmamados. Engenharia Agrícola, 30(6), 1003-1011.

Vermeer, H. M., Kuijken, N., \& Spoolder, H. A. (2009). Motivation for additional water use of growing-finishing pigs. Livestock Science, 124(1-3), 112-118. 